It has been shown previously (Breckenridge et al., 1971; Breckenridge and Orme, 1971; Orme et al., 1972) that of the drugs studied dichloralphenazone, phenazone, quinalbarbitone, and amylobarbitone will increase the rate of warfarin metabolism while chlordiazepoxide, diazepam, nitrazepam, and methaqualone will not. This property was used as a marker in this study so that the time-course and extent of changes in plasma GGT activity could be compared with some changes in values known to reflect hepatic microsomal enzyme activity. It was found that the timing of the changes in plasma warfarin concentration was closely similar to that of changes in GGT activity. Both changes were observable by seven days, in most cases a plateau was reached after 10-15 days, and a return towards baseline values began immediately drug administration was stopped. It has been suggested previously that changes in serum GGT are found only after three months' treatment with inducing agents (Rosalki et al., 1971) but this was not confirmed in the present investigation.

Some evidence of a relation between drug dose and the increase in enzyme activity was also apparent. In those instances where a rise in GGT activity occurred, in over half the cases the increase took the GGT activity above the upper limit of normal. Thus the possibility of drug-induced changes in plasma GGT must influence the interpretation of raised GGT activities in suspected liver disease, especially when such raised levels occur unaccompanied by abnormalities in other tests of liver function (Whitfield et al., 1972).

Administration of three benzodiazepines, diazepam, nitrazepam, and chlordiazepoxide or methaqualone produced no change in steady state plasma warfarin concentration in four patients, but two of these patients showed a significant rise in plasma GGT activity. If these changes in plasma GGT activity reflect changes in the liver enzymes then these drugs may have caused an increase in liver GGT without an increase in the activity of enzymes concerned with drug oxidation. Alternatively, other factors, such as the effects of alcohol consumption, may have influenced GGT activity (Rosalki and Rau, 1972).

In view of these discrepancies between changes in rates of drug oxidation and plasma GGT activity, it appears that increases in the plasma GGT activity cannot always be used as an index of changes in the activity of liver microsomal enzymes concerned with drug oxidation since it might lead to both false-positive and false-negative results.

It remains to be proved that the increase in plasma GGT concentration produced by inducing agents is accompanied by an increase in hepatic GGT in man. Other possibilities are that other tissues such as the kidney or gut are the source of the increased plasma GGT or that the rate of catabolism of circulating GGT is altered or that these drugs produce hepatic damage of the type which is accompanied by an increase in plasma GGT activity in hepatobiliary disease. However, Rosalki et al. (1972) have reported that a wide range of serum enzymes other than GGT remained normal in patients in whom a raised serum GGT accompanied drug treatment. This last explanation, therefore, appears improbable. Ideo et al. (1972) have shown an increase in liver GGT content in rats treated with phenobarbitone, and our own preliminary observations support this.

Therefore, the most likely sequence of events seems to be that the induction of hepatic microsomal drug-metabolizing enzymes is accompanied by induction of hepatic GGT, which in most cases is released into the circulation. There may be differences between species, and individuals within a species, in the extent to which the GGT from the liver appears in the serum. The role of GGT in the liver and the effects of increased activity of this enzyme there are at present obscure.

\section{References}

Breckenridge, A., Orme, M. L'E., Thorgeirsson, S., Davies, D. S., and Brooks, R. V. (1971). Clinical Science, 40, 351 .

Breckenridge, A., and Orme, M. (1971). Annals of the New York Academy of Sciences, $179,421$.

Conney, A. H. (1967). Pharmacological Revierws, 19, 317.

Ideo, G., Morganti, A., and Dioguardi, N. (1972). Digestion, 5, 326.

Lewis, R. J., Inicki, L. P., and Carlstrom, M. (1970). Biochemical Medicine 4, 376.

Orme, M., Breckenridge, A., and Brooks, R. V. (1972). British Medical fournal, 3, 611 .

Rosalki, S. B., and Rau, D. (1972). Clinica Chimica Acta, 39, 41.

Rosalki, S. B., Rau, D., Tarlow, D., and Baylis, E. M. (1972). Proceedings of the 8th International Congress on Clinical Chemistry, Copenhagen.

Rosalki, S. B., Tarlow, D., and Rau, D. (1971). Lancet, 2, 376.

Szasz, G. (1969). Clinical Chemistry, 15, 124.

Whitfield, J. B., Pounder, R., Neale, G., and Moss, D. W. (1972). Gut, 13, 702 .

\title{
Morbidity from Acute Carbon Monoxide Poisoning at Three-year Follow-up
}

\author{
J. SIDNEY SMITH, S. BRANDON
}

British Medical fournal, 1973, 1, 318-321

\section{Summary}

Seventy-four survivors of acute carbon monoxide poisoning were followed up for an average of three years. In eight patients gross neuropsychiatric damage was directly attributable to the poisoning. Three patients had committed suicide and eight had died from other causes. Morbidity and mortality in those deliberately and accidentally poisoned was approximately equal.

\footnotetext{
University Department of Psychological Medicine, Royal Victoria Infirmary, Newcastle upon Tyne 1

J. SYDNEY SMITH, M.A.N.Z.C.P., D.P.M., Research Senior Registrar (Now Lecturer in Psychiatry, University of New South $W$ ales, Sydney, Australia) S. BRANDON, M.D., M.R.C. PSYCF., Nuffield Foundation Fellow in Psychiatry and Hononary Consultant Psychiatrist (Now Reader in Psychiatry, University of Manchester)
}

Of 63 patients alive at follow-up eight showed an improvement and $21(33.3 \%)$ a deterioration of personality after poisoning, and $27(43 \%)$ reported a subsequent impairment of memory. Deterioration of personality and memory impairment were highly correlated. The level of consciousness on admission to hospital in the acute phase of poisoning correlated significantly with the development of gross neuropsychiatric sequelae. These findings emphasize the importance of prompt and efficient treatment of carbon monoxide poisoning and the need to follow-up all cases in the anticipation of a relapsing course or the development of sequelae.

\section{Introduction}

Carbon monoxide (CO) acts pathogenically by displacing oxygen from the haemoglobin molecule, shifting the oxyhaemo- 
globin dissociation curve to the left, and possibly by combining with the other iron-containing pigments of the body. Tissue hypoxia results, the central nervous system and heart suffering the principal damage.

The incidence in survivors of long-term neuropsychiatric sequelae has been variously estimated at $0.3 \%$ (Shillito et al., 1936a), $0.8 \%$ (Shillito et al., 1936b), $1.0 \%$ (Kuroiwa et al., 1967), $2 \cdot 1 \%$ (Zahle, 1948, the only complete follow-up study), $4.1 \%$ (Simpson, 1963), and 10\% (Richardson et al., 1959). Garland and Pearce (1967) noted that almost every known neurological syndrome had been reported to occur after CO poisoning. E.C.G. abnormalities can persist for weeks after acute poisoning (Middleton et al., 1961; Cosby and Bergeron, 1963; Hayes and Hall, 1964; Shafer et al., 1965), and in followup studies (Orinius, 1968; Veil et al., 1970) E.C.G. abnormalities have been common, though their relation to $\mathrm{CO}$ poisoning has not been established. Hadley (1952) estimated the incidence of major cardiac sequelae at $0.7 \%$.

In a study of 206 episodes of acute $\mathrm{CO}$ poisoning of all degrees of severity occurring in the city of Newcastle upon Tyne (Smith and Brandon, 1970) $2 \cdot 2 \%$ of the survivors were known on discharge to be suffering permanent neuropsychiatric damage. However, prolonged periods of delirium had occurred in $20.3 \%$ of the survivors, suggesting that all degrees of functional or structural damage had resulted and that the incidence of permanent sequelae had been underestimated. This paper details the results of the follow-up of this cohort.

\section{Method}

Patients surviving acute suicidal or accidental $\mathrm{CO}$ poisoning in the years 1965-7 were identified from the casualty and admission registers of the general hospitals serving the Newcastle upon Tyne city area, only those domiciled in the city area at the time of poisoning being considered for follow-up. Patients who had attempted suicide with $\mathrm{CO}$ were matched by age to within five years and for sex, marital status, and year of exposure with patients who had been admitted to the Newcastle General Hospital with deliberate barbiturate overdosage. No controls were sought for those accidentally exposed to CO. Thus 51 patients who had attempted suicide with $\mathrm{CO}$ (CO-attempted suicides), 51 who had overdosed with barbiturates (control group), and 33 who had been accidentally exposed to CO (COaccidental group) were studied.

Of the 135 patients $124(91 \cdot 8 \%)$ were traced, and detailed information was obtained from either the patient or a first-degree relative or both in 122 . The mean interval of follow-up was 38.6 months for the CO-attempted suicides, $37 \cdot 1$ months for the control patients, and 36.3 months for the CO-accidental group. Formal interview of the patient, usually in his own home, was followed by the administration of the Wechsler memory scale, form 1 .

\section{Results}

Detailed information was obtained on 46 of the CO-attempted suicides, 48 of the controls, and 28 patients in the CO-accidental group. Comparison of these groups by age, sex, and marital status showed no significant differences except that the $\mathrm{CO}$ accidental group contained significantly fewer married persons than the other groups. Five $(10.9 \%)$ of the CO-attempted suicides, $10(20.8 \%)$ of the controls, and $4(14.3 \%)$ of the patients in the CO-accidental group gave a previous history of head injury with alteration of consciousness, stroke, or other central nervous system disease. Seven control patients were known epileptics and had taken overdoses of their antiepileptic medication. No patient in the other groups suffered epilepsy.

Of those attempting suicide with CO 44 had used household gas and one was overcome by black smoke after deliberately setting fire to her house. Of those accidentally exposed 9
$(32 \cdot 1 \%)$ had been poisoned at work- 5 while working on leaking gas mains, 2 in a mine accident, 1 by furnace fumes, and 1 by fumes from a petrol pump in a flooded cellar. Non-occupational sources of exposure included unlit gas appliances (5), gas leaks (4), coke furnaces (4), automobile exhaust fumes (2), gas appliances operated with insufficient ventilation (2), and fire (1). One patient was involuntarily exposed to coal-gas by two men executing a suicide pact.

In $9(19.5 \%)$ of the CO-attempted suicides and $7(25.0 \%)$ of the patients in the CO-accidental group the poisoning had not resulted in any obvious loss of consciousness. Of the COattempted suicides $5(10.9 \%)$ had been semicomatose and 2 $(4.3 \%)$ comatose on arrival at the hospital. The figures for the CO-accidental group were $1(3.6 \%)$ semicomatose and $4(14.3 \%)$ comatose. Five of the CO-attempted suicides $(10.9 \%)$ had abnormal reflexes, $8(17 \cdot 4 \%)$ suffered a prolonged period of delirium lasting from many hours up to four weeks, $2(4.3 \%)$ had signs of acute respiratory congestion, and $1(2 \cdot 2 \%)$ developed a cardiac arrhythmia. In the CO-accidental group 3 patients $(10.7 \%)$ showed abnormal reflexes, $7(25.0 \%)$ prolonged delirium, $2(7 \cdot 1 \%)$ acute respiratory congestion, and $1(3 \cdot 6 \%)$ congestive cardiac failure.

Twenty-five of the CO-attempted suicides (54.3\%) and 17 $(60.7 \%)$ of the patients in the CO-accidental group had received oxygen, and the carboxyhaemoglobin level had been measured in $17(36.9 \%)$ of the CO-attempted suicides and $7(25.0 \%)$ of the patients in the CO-accidental group. Thirty-three COattempted suicides $(71.6 \%)$ but only $9(32.1 \%)$ of the patients in the CO-accidental group were admitted to hospital.

Follow-up, either medical or psychiatric, was offered to 32 $(69 \cdot 4 \%)$ of the CO-attempted suicides but only $22(47 \cdot 7 \%)$ accepted this help. Four patients $(14.3 \%)$ in the CO-accidental group were offered follow-up and three $(10.7 \%)$ subsequently attended.

At three years $7(15.2 \%)$ of the CO-attempted suicides, 5 $(10.4 \%)$ of the controls, and $4(14.3 \%)$ of the patients in the CO-accidental group had died. Of the CO-attempted suicides one elderly man (case 10) died in another hospital without recovering from the initial episode and two patients committed suicide within a few months of their discharge from hospital. One patient in the control group died from barbiturate poisoning six months after discharge from hospital and one in the COaccidental group died by $\mathrm{CO}$ poisoning following an influenzalike illness and depression three years after the index episode.

In $5(10.9 \%)$ of the CO-attempted suicides and $3(10.7 \%)$ patients in the CO-accidental group gross neuropsychiatric sequelae in the form of cognitive change, personality change, or frank neurological abnormality was directly and unequivocally the result of $\mathrm{CO}$ poisoning. All eight patients were comatose before admission though three regained consciousness by the time of admission to hospital. One of these-case 10-was mentioned above. Another elderly man (case 17), who had previously shown possible early signs of dementia, developed marked intellectual deterioration after deliberate poisoning. In a previously normally developing 6-year-old (case 62) accidental exposure was followed by severe intellectual deterioration and a speech defect. In two patients (cases 88 and 116) the diagnosis of cerebral damage was made on the basis of gross personality change and subjective complaints of memory impairment. In case 118 accidental exposure produced an organic personality change with a defective short-term memory; these difficulties so distressed the patient that he attempted suicide with $\mathrm{CO}$ one month later. On this occasion after recovery from a period of coma he relapsed into an akinetic mute state with the subsequent development and partial recovery from a dementing process with dyspraxia and dysphasia. In the control group no brain damage could be attributed directly to the overdose (Smith $e t$ al., 1971).

Case 10.-A 73-year-old single man had attempted suicide with $\mathrm{CO}$. On admission to hospital he was delirious. No oxygen was given and the carboxyhaemoglobin level was not measured. He was discharged 
the same day and the mental welfare officer was notified. However, he remained delirious, his neighbours noting his confusion and disorientation. Two days after the poisoning he was detained by the police for indecent exposure and transferred to the local mental hospital, where he was noted to be in congestive cardiac failure and subsequently developed bronchopneumonia. He died 15 days later. As the personnel of the mental hospital were not aware of his CO poisoning it was presumed that his condition was the result of cerebral arteriosclerosis, and no specific treatment was given.

Case 116.-A 33-year-old healthy and emotionally stable miner was accidentally exposed to $\mathrm{CO}$ in a coal-mine explosion. He was comatose when found some minutes later and subsequently was noted to be delirious, irritable, and aggressive for four hours. Oxygen therapy was given and he was discharged from hospital the same day. Subsequently he was forgetful, had difficulty in coping with his previous level of work, was increasingly irritable, restless, and argumentative, and on occasions was violent towards his wife. He was more impulsive and outspoken, more anxious, and more prone to paranoid misinterpretations. His physical energy had markedly diminished. In the month before the interview he had been charged with indecent assault on five young girls. His wife verified his previously stable personality and deterioration of memory and personality change subsequent to exposure. An independent witness unaware of the patient's fate after the accident attested to his previous stable personality. Financial compensation had never been considered.

Six patients were thought to be suffering neuropsychiatric impairment not directly related to the poisoning. One of the CO-attempted suicides had suffered anoxic brain damage from drowning one year before the poisoning. Two of the control patients were demented from causes preceding the overdose, one a result of numerous cerebrovascular accidents and the other a presumed senile dementia. In the $\mathrm{CO}$-accidental group one patient had shown evidence of dementia before the poisoning, in another dementia had developed after a cerebrovascular accident, and a third patient, a 7-year-old girl, was found to be hyperkinetic with gross E.E.G. evidence of temporal lobe disease.

Among those alive at the time of follow-up personality change of a favourable kind was reported subsequent to the poisoning in $7(15.2 \%)$ of the CO-attempted suicides, $12(27.9 \%)$ of the controls, and $1(4.2 \%)$ of the patients in the CO-accidental group, most being adolescents who had achieved some degree of maturity. An account of deterioration of personality was obtained in $16(34.7 \%)$ of the CO-attempted suicides, $4(9.3 \%)$ of the controls, and $5(20.8 \%)$ of the patients in the COaccidental group. The difference between the CO-attempted suicides and the control patients was highly significant $\left(\chi^{2}=\right.$ $11 \cdot 16$, D.F. $=1, P<0.001)$. The commonest change was increased irritability, verbal aggressiveness, violence, impulsiveness, and moodiness-a constellation that might be termed "affective incontinence."

Deterioration of memory subsequent to the poisoning was noted by patient or informant in $19(41.2 \%)$ of the CO-attempted suicides, $11(25.6 \%)$ of the controls, and $8(33.3 \%)$ of the patients in the CO-accidental group. The difference between the CO-attempted suicides and the controls was statistically significant $\left(\chi^{2}=4.72\right.$, D.F. $\left.=1, P<0.05\right)$. Complaints of memory impairment and a low memory quotient were highly correlated ( $r=0.441, P<0.001$ ). Accounts of personality deterioration correlated highly with complaints of memory deterioration $(\mathbf{r}=$ $0.423, P<0.001)$ and a low memory quotient $(r=0.371$, $P<0.001)$.

Thus over and above the $10.8 \%$ suffering gross neuropsychiatric sequelae from $\mathrm{CO}$ poisoning there appears to have been a large number who suffered milder forms of brain damage in the form of personality and affective change of an irritable, aggressive, and violent type with associated cognitive impairment.

A 46-year-old man suffered angina on exertion from the time of his deliberate exposure, and a 37-year-old man developed a myocardial infarct within hours of his accidental exposure and subsequently experienced angina and intermittent congestive heart failure. Both of these patients had family histories of ischaemic heart disease. In another accidentally exposed patient ischaemic heart disease and congestive cardiac failure were diagnosed some months after the poisoning.
No damage to any other organ was directly attributable to $\mathrm{CO}$ poisoning. Of the $46 \mathrm{CO}$-attempted suicides $7(15.2 \%)$ had been subsequently admitted to hospital for medical reasons and 6 $(13.0 \%)$ for surgery. The corresponding figures for the 48 control patients were $6(12.5 \%)$ and $12(25.0 \%)$, and for the 28 patients in the CO-accidental group $5(17.9 \%)$ and $5(17.9 \%)$ respectively.

The development of neuropsychiatric sequelae from CO poisoning correlated significantly with the level of consciousness on admission $(r=0.352, P<0.05)$ but not with the presence of abnormal reflexes $(r=0.238, P<0.1)$ or a prolonged period of delirium $(r=-0.020, P>0.1)$. The level of consciousness on admission correlated significantly with complaints of memory impairment by patient or informant $(r=0.349, P<0.05)$ and with a low memory quotient $(r=0.335, P<0.05)$.

\section{Discussion}

Of the 74 patients followed up for an average of three years after acute CO poisoning $10 \cdot 8 \%$ were suffering neuropsychiatric sequelae. In addition $4.0 \%$ had committed suicide and $10.8 \%$ had died from other causes. The incidence of morbidity and mortality in those accidentally and deliberately poisoned was about equal. Neuropsychiatric damage was five times more common than had previously been estimated (Smith and Brandon, 1970). In some cases defects such as Parkinsonism, intellectual change, and organic personality change had become evident only after the patient's discharge from hospital, emphasizing the importance of following up every case for an interval which allows for the delayed onset of sequelae. The fact that $28.0 \%$ of those deliberately exposed to $\mathrm{CO}$ and $67.9 \%$ of those accidentally exposed had received no more than treatment in a casualty department and that only $48.0 \%$ and $10.7 \%$ respectively had received follow-up care hindered the recognition of sequelae. The temporal relationship of the sequelae to the $\mathrm{CO}$ poisoning was often appreciated by the patients and their informants but not by their physicians. In the comparable follow-up study of Zahle (1948) the incidence of neuropsychiatric sequelae was lower, but his patients were younger, fewer had been comatose as a result of the poisoning, and organic personality change was not considered.

The predilection of layers 2 and 3 of the cerebral cortex, the globus pallidus, Sommers's sector and end-plate of the hippocampus, the Purkinje cell layer of the cerebellum, and the white matter of the cerebral hemispheres to damage from CO poisoning has been shown at necropsy (Meyer, 1963). However, no central nervous tissue is immune to damage, and even peripheral nerve disease has been reported (Wilson and Winkleman, 1924). In the present study one patient at follow-up was suffering parietal lobe damage with dyspraxia and dysphasia and another basal ganglia damage with Parkinsonism. No clinical evidence of damage to pyramidal tracts, long ascending tracts, cerebellum, spinal cord, cranial nerves, and peripheral nerves was observed. Severe global deterioration of cognitive function occurred in five cases; however, in $41.2 \%$ of patients deliberately exposed and $33.3 \%$ of those accidentally exposed either the patient or the informant gave a history of memory impairment subsequent to the poisoning. Those attempting suicide with $\mathrm{CO}$ were significantly more likely than the control patients to complain of such memory difficulties even though premorbid cerebral disease was commoner in the controls. The high intercorrelation of complaints of memory impairment, objective evidence of memory impairment as measured by the Wechsler memory scale, and complaints of personality change, especially of the "affective incontinence" type, suggests that in many patients brain damage may have occurred at the subcortical level.

In two patients cardiac damage first became evident at the time of the $\mathrm{CO}$ poisoning. In retrospect, however, the pathogenic role of $\mathrm{CO}$ cannot be determined, especially as both patients had family histories of ischaemic heart disease. No damage to any other organ was directly attributable to CO poisoning. 
Depth of coma and the presence of abnormal plantar reflexes in the acute stage of poisoning were considered by Zahle (1948) to correlate with the development of neuropsychiatric sequelae, while Bokonjic (1963) determined that the duration of coma, the advancing age of the patient, and the development of cardiovascular failure indicated a poor prognosis for both survival and the recovery of mental functions. In the current study the level of consciousness on admission correlated with the development of gross neuropsychiatric sequelae, but the correlation with reflex abnormalities failed to reach a significant level; prolonged periods of delirium associated with poisoning and advancing age were not of prognostic significance, and only one patient had been in cardiac failure on admission. A relapsing course had occurred in one patient developing a dementing process. Oxygen therapy had been reserved for the more severely affected patients, so that the consequence of failing to administer oxygen could not be established, and the carboxyhaemoglobin levels had been estimated on too few patients to allow any conclusions. Subjective complaints and objective evidence of memory impairment were also related to the level of consciousness on admission.

The frequency of acute $\mathrm{CO}$ poisoning in Great Britain is sharply declining (Office of Health Economics, 1972), but the high mortality rate and the considerable morbidity in the survivors call for continuing efforts to prevent acute poisoning and to treat promptly those exposed. The lowering of the $\mathrm{CO}$ content of town gas has reduced the frequency of accidental and suicidal exposure (Gremy et al., 1968; Hassall and Trethowan, 1972), but inadequate ventilation and flueing of appliances burning natural gas can produce high levels of $\mathrm{CO}$ with fatal consequences (Ministry of Technology, 1970). Firemen may be exposed to black smoike, and the possibility that patients sustaining burns from fires in enclosed spaces may be suffering severe CO poisoning should always be considered (Pollard, 1970). The internal combustion engine is likely to continue as a source of exposure.

Our findings suggest that the hazards of $\mathrm{CO}$ poisoning are not always appreciated by casualty officers, and as it becomes less common the dangers of unfamiliarity are increased. In our view every patient exposed to $\mathrm{CO}$ should receive prompt and efficient oxygenation including hyperbaric therapy where available, and the early reduction of cerebral oedema with hypertonic solutions or steroids may be of value. The importance of providing follow-up facilities in the anticipation of a relapsing course or the delayed development of neuropsychiatric and cardiac sequelae has been established.

We wish to thank Mrs. P. Walker for her invaluable work in the tracing of patients, and all of our colleagues who helped in this tracing and made their clinical records available to us. The advice and assistance of Professor M. Roth on the conduct of the study and the editorial notes of Professor L. Kiloh are greatly appreciated. This study was supported by grants from the scientific and research committee of the Royal Victoria Infirmary and Pfizer Pty. Ltd.

Requests for reprints should be addressed to Dr. S. Brandon, Department of Psychiatry, Gaskell House, Swinton Grove, Manchester 13.

\section{References}

Bokonjic, N. (1963). Electroencephalography and Clinical Neurophysiology,

Cosby, R. S., and Bergeron, M. (1963). American fournal of Cardiology, 11,

Fields, F. R. J. (1971). Diseases of the Nervous System, 1, 673

Garland, H., and Pearce, J. (1967). Quarterly fournal of Medicine, 36, 445 Gremy, F., Salmon, D., Francois R.-C., and Bertin, M. (1968). Presse Medicale, 76, 1099.

Hadley, M. (1952). British Heart Fournal, 14, 534.

Hassall, C., and Trethowan, W. H. (1972). Suicide in Birmingham, vol. 1, p. 717 .

Hayes, J. M., and Hall, G. V. (1964). Medical fournal of Australia, 1, 865. Kuroiwa, Y., Shida, K., Nagamatsu, K., Kato, M., and Santa, T. (1967). Folia Psychiatrica et Neurologica faponica, 21, 189.

Meyer, A. (1963). In Greenfield's Neuropathology, 2nd edn. London, Arnold. Middleton, G. D., Ashby, D. W., and Clark, F. (1961). Lancet, 1, 12. Ministry of Technology (1970). Report of Inquiry into Safety of Natural Gas

Office of Health Economics (1972). Information Sheet, No. 18: Suicide. London, O.H.E.

Orinius, E. (1968). Acta Medica Scandinavica, 183, 239.

Pollard, J. A. (1970). British fournal of Surgery, 57, 635

Richardson, J. C., Chambers, R. A., and Heywood, P. M. (1959). Archives of Neurology, 1, 178.

Shafer, N., Smilay, M. G., and MacMillan, F. P. (1965). American fournal of Medicine, 38, 316.

Shillito, F. H., Drinker, C. K., and Shaughnessy, T. J. (1936 a). fournal of the American Medical Association, 106, 669.

Shillito, F. H., Drinker, C. K., and Shaughnessy, T. J. (1936 b). American Gas Association Monthly, 260.

Simpson, C. A. (1963-5). Newcastle Medical fournal, 28, 67.

Smith, J. S. And Brandon, S. (1970). Postgraduate Medical fournal, 46, 65 Smith, J. S., Brierley, H., and Brandon, S. (1971). Psychological Medicine, 1 172 .

Veil, C., et al. (1970). Annales Médico-Psychologiques, 2, 343.

Wilson, G., and Winkleman, N. W. (1924). Fournal of the American Medical Association, 82, 1407

Zahle, V. (1948). Kliniske Studie Med. Saerlig Henblik Paa Komplikationerne. Aarhus, Universitetsforlaget.

\title{
The Wounded Uterus: Pregnancy after Hysterotomy
}

\author{
W. M. CLOW, A. C. CROMPTON
}

British Medical fournal, 1973, 1, 321-323

\section{Summary}

Despite contraceptive advice, a high proportion of patients who have had a pregnancy terminated by hysterotomy became pregnant again within a short space of time. Fifty-three such pregnancies have been studied, and a substantial risk of rupture of the uterus was demonstrated in 14 cases where the scar was thin. Rupture, impending rupture, or presump-

St. Mary's Hospital, Manchester M13 0JH

W. M. CLOW, M.B., M.R.C.O.G., Clinical Tutor

A. C. CROMPTON, M.D., M.R.C.O.G., Lecturer, Department of Obstetrics and Gynaecology. (Present appointment: Consultant Obstetrician and Gynaecologist, St. James's University Hospiatl, Leeds.)

tive rupture occurred in three of these cases. Nevertheless successful vaginal delivery occurred in about $80 \%$ of cases. The infants so produced were often small for dates. Due weight should be given to the risks of subsequent early pregnancy and uterine rupture before terminating a pregnancy by the operation of hysterotomy without sterilization.

\section{Introduction}

Since the implementation of the Abortion Act in 1967 hysterotomy has been the method of termination adopted for about $25 \%$ of patients (Registrar General, 1970, 1971). Sood (1971), Stallworthy et al. (1971), and Brown et al. (1971) have shown that this method carries a high morbidity. Peel (1970) and Lewis (1969) suggested that the increased use of this operation, un- 